\title{
Varones 46, XX: a propósito de dos casos genéticamente distintos
}

\section{Males 46, XX: Presentation of Two Genetically Different Cases}

\author{
Arianne Llamos Paneque ${ }^{1}$ Stefany Montúfar Armendáriz ${ }^{1}$ Carlos Alberto Reyes Silva ${ }^{2}$ \\ Maribel de los Ángeles Garzón Castro ${ }^{1}$ Nina Jacinta Tambaco Jijón ${ }^{1}$
}

${ }^{1}$ Hospital de Especialidades FFAA No.1, Quito, Pichincha, Ecuador
${ }^{2}$ Hospital de Especialidades Eugenio Espejo, Quito, Pichincha, Ecuador Urol Colomb 2019;28:80-87.
Address for correspondence Arianne Llamos Paneque, MD, Hospital de Especialidades FFAA No.1, Av. Queseras del Medio No. 521 y Gran Colombia, Quito, Pichincha, Ecuador (e-mail: allamosp@he1.mil.ec).

\section{Resumen \\ Palabras Clave \\ - desorden del desarrollo sexual \\ - gen SRY \\ - hipogonadismo \\ - citogenética \\ - desarrollo sexual \\ - cariotipo}

\section{Abstract}

received

June 27, 2018

accepted

August 14, 2018

published online

October 1, 2018
Introducción Los desórdenes de diferenciación sexual son condiciones clínicas en las que existe una discrepancia entre el sexo cromosómico y el sexo fenotípico de un individuo. Esas condiciones suelen resultar angustiantes para los pacientes y sus familias e incluso para el equipo médico tratante debido a la dificultad en diagnosticarlas.

Objetivo Presentar las características clínicas, genéticas y hormonales de dos varones con desórdenes de diferenciación sexual.

Método Se realizó un estudio descriptivo basado en la revisión y análisis de datos de la historia clínica y la confrontación de los resultados con reportes similares.

Resultados Se observaron dos individuos con fenotipo masculino y diagnóstico de hipogonadismo hipergonadotrófico con cariotipo 46, XX. El primer caso presentó testes pequeños y azoospermia, mientras que el segundo caso presentó baja talla, criptorquidea bilateral congénita y escrotos hipoplásicos. En ambos pacientes se exploró la presencia del gen SRY, confirmando su presencia en el primer caso y ausencia en el segundo caso.

Conclusiones El diagnóstico genético-molecular actual apela a la combinación de técnicas tradicionales junto a técnicas modernas, como secuenciación por paneles genéticos a fin de identificar etiológicamente los desórdenes de diferenciación sexual. La presentación de esos casos aún se considera rara debido a su baja tasa de frecuencia poblacional, por lo que su reporte siempre resultará útil a la comunidad científica ya que muestran las distintas formas de presentación clínica y el manejo multidisciplinario de esos casos en diferentes contextos clínicos.

Introduction Disorders of Sexual Development are clinical conditions in which a discrepancy between the chromosomal sex and the phenotypic sex occurs in an individual. These conditions are often distressing for patients and their families and even for the medical team due to the difficulty of diagnosing them.

Objective The aim of this study was to present the clinical, genetic and hormonal characteristics of two males with sexual differentiation disorders. 


\author{
Keywords \\ - disorder of sexual \\ development \\ - SRY gene \\ - hypogonadism \\ - cytogenetics \\ - sexual development \\ - karyotype
}

Method A descriptive study was performed based on the review and analysis of the clinical history data and the comparison of the results with similar cases reported. Results Two individuals with a male phenotype and a diagnosis of hypogonadotropic hypogonadism with 46, XX karyotype were observed. The first case presented small testes and azoospermia, while the second case presented low height, congenital bilateral cryptorchid and hypoplastic scrotums. The SRY gene was explored in both patients, and it was confirmed its presence in the first case and its absence in the second case.

Conclusions The current molecular-genetic diagnosis calls for the combination of traditional techniques combined with modern techniques, such as the genetic panel sequencing, to identify etiologically the Disorders of Sexual Development. The presentation of these cases is even considered rare because of their low population frequency rate, so their report is always useful to the scientific community, for they show the different ways of the clinical disease presentation and the multidisciplinary management of these cases in different clinical contexts.

\section{Introducción}

Los Desórdenes de la Diferenciación Sexual (DSD, por sus siglas en inglés) son condiciones poco frecuentes en las que no existe concordancia entre el sexo cromosómico o genético y el sexo fenotípico de un individuo. Los varones XX, (DSD 46, $\mathrm{XX}$ ) son un tipo de DSD que se conoce también como síndrome La Chapelle, en referencia al autor que describió esa entidad por primera vez en $1964 .^{1}$ Se estima que esa rara condición se presenta en uno de cada 20.000 nacimientos. ${ }^{2}$ Esos pacientes frecuentemente presentan uno de estos tres fenotipos:

1) Fenotipo masculino, genitales externos masculinos, que son referidos fundamentalmente por infertilidad o hipogonadismo.

2) Ambigüedad genital de grado variable detectada al nacimiento, dentro de las que destacan micropene, hipertrofia del clítoris, hipospadias.

3) Hermafroditismo verdadero, con ambigüedad genital y ovotestes. $^{3-5}$

El 80 al 90\% de los varones con cariotipo convencional en sangre periférica $46, \mathrm{XX}$ son SRY positivos (+) y presentan un grado normal de virilización, mientras que el $10 \%$ restante son SRY negativos (-) con grados de virilización incompleta. ${ }^{6}$

El gen SRY está ubicado en el brazo corto del cromosoma Y, inmediatamente debajo de la región pseudoautosómica. Este gen es el principal desencadenante de la diferenciación al sexo masculino, pues inicia un conjunto de eventos en cascada que conducen a la evolución de la cresta genital indiferenciada hacia el testículo. ${ }^{7,8}$

En la mayoría de los casos 46, XX SRY (+) se produce una translocación del gen SRY al cromosoma X en virtud de un apareamiento meiótico desigual en la gametogénesis paterna. En otros casos más raros, el gen SRY se transloca hacia un cromosoma autosómico. Los varones 46 , XX SRY (-) ponen en evidencia la necesaria participación de otros genes en la diferenciación testicular. ${ }^{8}$
En este trabajo se presenta el comportamiento clínico, genético y bioquímico de dos varones 46 , XX con el objetivo de mostrar aspectos claves en el algoritmo diagnóstico de esas condiciones, que si bien son de baja prevalencia, constituyen un reto para el equipo médico tratante.

\section{Materiales y Métodos}

Las historias clínicas de ambos pacientes fueron revisadas con énfasis en obtener la información referida a antecedentes pre, peri y postnatales, resultados de estudios hormonales, ecográficos, de laboratorio y genéticos. Ambos pacientes recibieron evaluación clínico-genética y se elaboró la genealogía familiar incluyendo tres generaciones filiales. El consentimiento informado fue solicitado y firmado en ambos casos, siempre protegiendo la identidad de cada paciente.

Se realizó cariotipo convencional mediante cultivo de linfocitos obtenidos por punción de vena periférica, aplicando bandeo GTG y conteo de 20 metafases con resolución de 550 bandas.

Para el estudio molecular del cromosoma Y, se aplicó la técnica de la Reacción en Cadena de la Polimerasa (PCR) utilizando el kit Y Chromosome AZF Analysis System (Promega Corporation, Madison, WI USA) mediante cinco reacciones multiplex separadas (A, B, C, D y E) que permiten detectar la presencia o ausencia de 20 regiones específicas del cromosoma Y como se detalla en la Tabla 1. La visualización de los fragmentos amplificados se realizó a través de electroforesis horizontal en gel de agarosa grado analítico al $4 \%(\mathrm{p} / \mathrm{v})$.

\section{Caso 1}

Paciente ecuatoriano de género masculino, 24 años de edad, acude al Servicio de Genética Médica del Hospital de Especialidades Fuerzas Armadas No.1, Quito-Ecuador, referido desde la Red Integral Pública de Salud por la especialidad de Endocrinología para estudio de hipogonadismo. 
Tabla 1 Regiones cromosómicas incluidas en las reacciones múltiplex de la PCR

\begin{tabular}{|c|c|c|c|c|c|c|c|}
\hline \multirow[t]{2}{*}{ Mix A } & LOCUS & DAZ & DYS240 & DYS271 & DYS221 & KAL-Y & SMCX \\
\hline & STS & SY254 & SY157 & SY81 & SY130 & SY182 & \\
\hline \multirow[t]{2}{*}{ Mix B } & LOCUS & SMCY & DYS218 & DAZ & DAZ & SMCX & \\
\hline & STS & SY2PR3 & SY127 & SY242 & SY208 & & \\
\hline \multirow[t]{2}{*}{ Mix C } & LOCUS & DYS219 & DYS212 & DYF51S1 & DAZ & SMCX & \\
\hline & STS & SY128 & SY121 & SY145 & SY255 & & \\
\hline \multirow[t]{2}{*}{ Mix D } & LOCUS & DYS223 & DYS236 & DYS215 & SMCX & & \\
\hline & STS & SY133 & SY152 & SY124 & & & \\
\hline \multirow[t]{2}{*}{ Mix E } & LOCUS & ZFX/ZFY & SRY & DYS224 & DYS148 & DYS273 & \\
\hline & STS & & SY14 & SY134 & SY86 & SY84 & \\
\hline
\end{tabular}

El paciente no refiere antecedentes familiares relevantes y presenta historia de buena salud personal. Mediante examen físico se constata una talla de $163 \mathrm{~cm}$, peso de $69 \mathrm{~kg}$, brazada de $165 \mathrm{~cm}$, IMC de 26, vello axilar y púbico normal, pene de tamaño normal, testículos pequeños de $3,4 \mathrm{~mL}$, no ginecomastia, voz varonil, no anosmia o hiposmia.

Los resultados del perfil hormonal, estudio ecográfico y espermograma se resumen en la Tabla 2.

En el estudio genético, el cariotipo evidenció la presencia de dos cromosomas Xy ausencia del cromosoma $Y$ (-Fig. 1), mientras que el análisis molecular reveló la presencia del gen SRY con ausencia de las otras regiones específicas del cromosoma Y (-Fig. 2).

\section{Caso 2}

Paciente ecuatoriano de género masculino, 11 años de edad, acude al Servicio de Genética Médica del Hospital de Especialidades Fuerzas Armadas No.1, Quito-Ecuador, referido desde la Red Integral Pública de Salud por la especialidad de Endocrinología Pediátrica para estudio de escrotos vacíos.

En su historia personal resalta haber nacido con criptorquidia bilateral congénita para lo cual le realizaron orquidopexia a los cinco años de edad. Además, el paciente no refiere antecedentes familiares relevantes.

Tabla 2 Datos clínicos del Caso 1

\begin{tabular}{|l|l|}
\hline Parámetros & Caso 1 \\
\hline FSH $(\mathrm{mUl} / \mathrm{mL})$ & 18 \\
\hline LH $(\mathrm{mUl} / \mathrm{mL}$ & 26.9 \\
\hline $17 \mathrm{OH}$ progesterona & No se ha realizado \\
\hline Testosterona total $(\mathrm{ng} / \mathrm{dL})$ & 299 \\
\hline Tipo de hipogonadismo & Hipergonadotrópico \\
\hline Espermograma & Azoospermia \\
\hline Biopsia testicular & No se ha realizado \\
\hline Ecografía testicular & Atrofia testicular bilateral \\
\hline
\end{tabular}

Mediante examen físico se constató talla de $113 \mathrm{~cm}$ (baja talla por debajo del 3er Percentil), peso de $26 \mathrm{~kg}$, brazada de $108 \mathrm{~cm}$, IMC de 20,33, cuello corto, teletelia, tórax ancho y longitud del pene de $5 \mathrm{~cm}$. También, el paciente presenta bolsas escrotales vacías y se palpa hacia la región supra púbica una tumoración blanda que parece corresponder al testículo derecho.

Los resultados del perfil hormonal, estudios ecográficos, anatomopatológicos y estudios genéticos se resumen en la Tabla 3.

En el estudio genético, el cariotipo evidenció la presencia de dos cromosomas X y ausencia del cromosoma Y (-Fig. 3 ). El análisis molecular demostró la ausencia de 20 sitios específicos de la región AZF (Factor de azoospermia) del cromosoma Y incluyendo el gen SRY (-Fig. 4).

\section{Discusión}

Los casos presentados muestran dos espectros clínicos diferentes de los DSD 46, XX, tanto desde el punto de vista genético con presencia y/o ausencia del gen SRY así como desde el punto de vista fenotípico con virilización completa versus virilización incompleta.

En el caso 1, la sospecha diagnóstica inicial fue Síndrome de Klinefelter por el tamaño reducido de los testes asociado a un hipogonadismo hipergonadotrópico que es la patología más frecuente a descartar en esos casos. Sin embargo, una somatometría corporal sin hábito eunucoide y una talla menor a la esperada para los casos 47, XXY pueden ser indicios a considerar en el diagnóstico diferencial clínico, aspecto que fue evidenciado y en el que coinciden varios autores. 9,10

Los resultados de los estudios de biología molecular constataron la presencia del gen SRY en el caso 1. En una amplia revisión de la literatura de los últimos años sobre la base de una investigación de fertilidad masculina, Majzoub y col., (2017) describe una serie significativa de varones 46, XX en los que se detectó mediante FISH la presencia del gen SRY en el $83,7 \%$ de los casos $(n=49){ }^{11}$ La presencia del gen SRY se reconoce como el principal factor determinante en la virilización. ${ }^{8}$ Sin embargo, otros genes de la región AZF juegan también un rol determinante en la espermatogénesis 


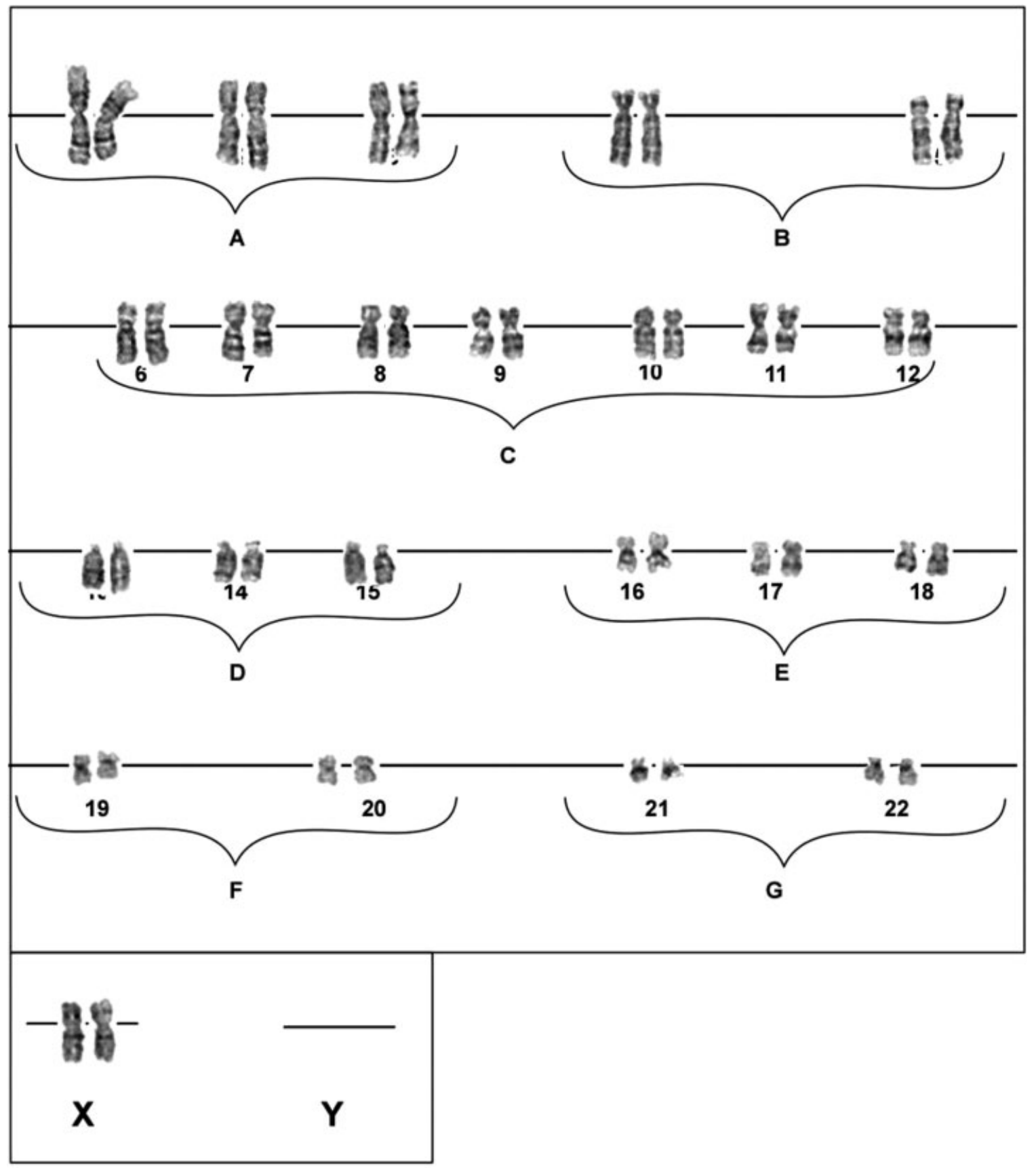

Fig. 1 Cariotipo de Caso 1 con técnica de bandeo GTG, 46, XX.

y podrían ser los responsables de la azoospermia que se constató en este paciente donde esa región estuvo totalmente ausente. ${ }^{12}$

El genotipo observado en el caso 1, sugiere una translocación del gen SRY a otro cromosoma que no fue posible definir con exactitud al no realizar el estudio FISH. La ubicación cromosómica de esa translocación no se consideró imprescindible para este caso tomando en cuenta el resultado del estudio molecular realizado. Obsérvese que todas las regiones del cromosoma $\mathrm{Y}$ exploradas, que incluyeron 19 regiones comprendidas en la región AZF, estuvieron ausentes. Este resultado indica una selectividad del gen SRY en la presunta translocación causal.
La edad al diagnóstico coincide con la reportada en la literatura que se estima entre 24 a 34 años $^{13}$ y el fenotipo presentado ha sido reportado en otras series publicadas donde el aspecto masculino normal, la talla promedio de $1,66 \mathrm{~cm} \pm 6$, la azoospermia y el hipogonadismo hipergonadotropico han sido las características más relevantes. ${ }^{11}$ Generalmente, para estos casos con virilización normal, la sospecha diagnóstica se establece en la adultez temprana a consecuencia de infertilidad. Es curioso que, en nuestro paciente, la infertilidad no resultara en el motivo inicial para los estudios sino la constatación de unos testes muy pequeños, en el contexto de un examen médico para ingresar a una Institución Armada. 


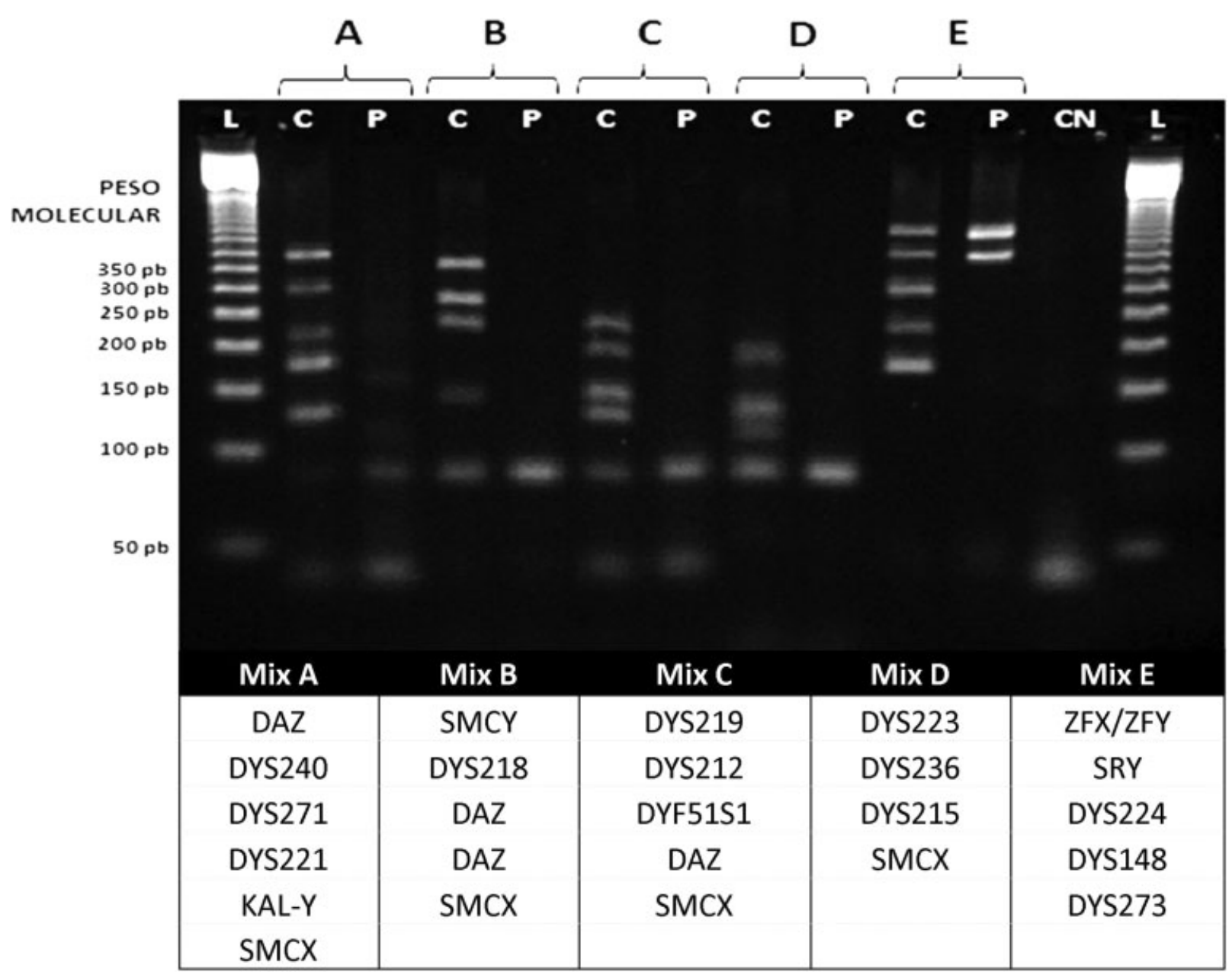

Fig. 2 Gel de agarosa grado analítico 4\% (p/v). Abreviaciones: CM, control masculino; CN, control negativo; L, marcador de peso molecular de 50 bp; P, paciente caso.

Tabla 3 Datos clínicos del Caso 2

\begin{tabular}{|c|c|}
\hline Parámetros & Caso 2 \\
\hline $\mathrm{FSH}(\mathrm{mUl} / \mathrm{mL})$ & 8 \\
\hline $\mathrm{LH}(\mathrm{mUl} / \mathrm{mL}$ & 16 \\
\hline $17 \mathrm{OH}$ progesterona & Normal \\
\hline $\begin{array}{l}\text { Testosterona total } \\
\text { (ng/dL) }\end{array}$ & 32 \\
\hline $\begin{array}{l}\text { Tipo de } \\
\text { hipogonadismo }\end{array}$ & Hipergonadotrópico \\
\hline Ecografía testicular & 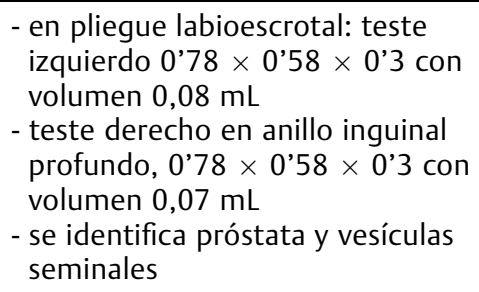 \\
\hline Biopsia testicular & $\begin{array}{l}\text { Tejido testicular conservado de } \\
\text { gónada derecha e izquierda }\end{array}$ \\
\hline Espermograma & No realizado por edad del paciente \\
\hline
\end{tabular}

Debe considerarse que la ausencia de genes del cromosoma $\mathrm{Y}$ que se reconocen implicados en el crecimiento puberal y el efecto de la testosterona en la talla final de un individuo, son factores que podrían explicar la baja talla observada en nuestro caso y que suelen caracterizar a varones $46, \mathrm{XX}$ SRY $(-)^{9}$

En contraste, el caso 2 presentó ausencia del gen SRY, situación que se describe en alrededor del $10 \%$ de pacientes varones $46, \mathrm{XX} \cdot{ }^{6,10}$ Su detección a la edad de 11 años, facilitó el acompañamiento médico y psicológico precoz. Llama la atención la historia de orquidopexia referida a los 5 años de edad, situación ya antes reportada en otros casos en los que la presencia de criptorquidia bilateral congénita sin descenso antes de los dos años de edad, habría llevado a cirugías correctoras. $^{14}$

Esos reportes ilustran que la realización de estudios citogenéticos previos a decisiones quirúrgicas, si bien no es imprescindible en todas las criptorquidias, debería considerarse de primera línea en pacientes nacidos a término con criptorquidia bilateral persistente y más aún si se asocia a baja talla. 


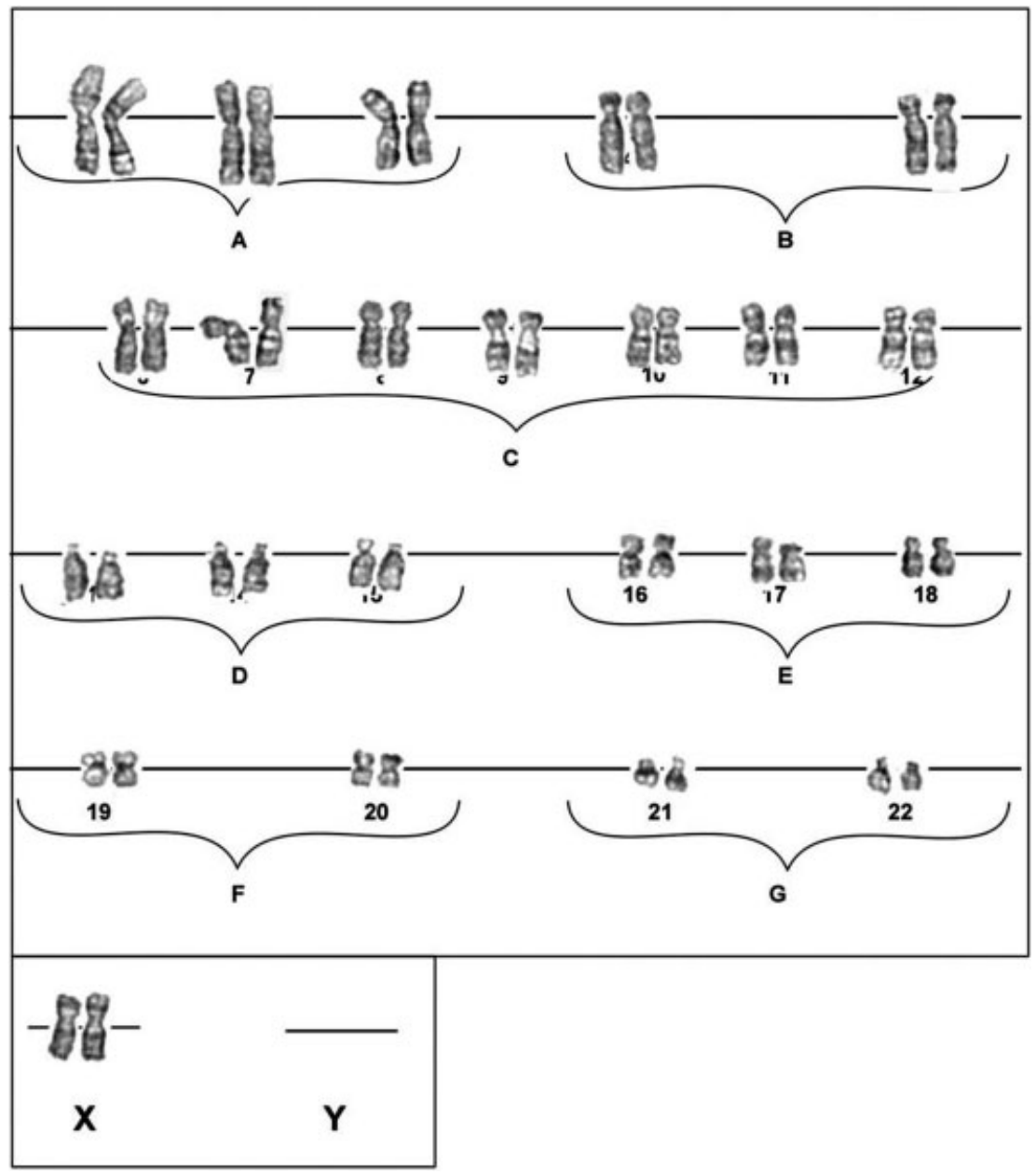

Fig. 3 Cariotipo de Caso 2 con técnica de bandeo GTG, 46, XX.

La hipótesis de un posible mosaicismo bajo de línea Y que sea capaz de explicar el desarrollo testicular observado en el segundo caso es la menos probable, pues si bien a nivel citogenético podría no ser detectado, los resultados moleculares son contundentes ya que ninguno de los 20 sitios específicos de la región AZF del cromosoma Yamplificó mediante la PCR. Por otro lado, la hipótesis de una posible mutación en un gen autosómico, implicado en la cascada de la diferenciación testicular, queda entre abierta y refuerza la necesidad de la complementación de este caso a través de estudios con paneles genéticos de diferenciación sexual donde podrían destacar los defectos genéticos en los receptores de las hormonas peptídicas, los miembros de la superfamilia de los receptores esteroideos y otros factores de transcripción, así como cualquiera de una serie de enzimas y cofactores que intervienen en la biosíntesis de los esteroides y que pueden inducir la determinación sexual. ${ }^{15}$ Otros autores han defendido la presencia de diferentes genes determinantes del sexo localizados en células autosómicas que al parecer también inician el proceso de "masculinidad." Por ejemplo, se sabe que el gen SOX9, ubicado en el brazo largo del cromosoma 17, potencia los efectos del gen SRY y su sobreexpresión se ha relacionado con $46, \mathrm{XX}$ varones SRY negativos. ${ }^{16}$
El manejo de ambos pacientes se centró en su inserción a un equipo multidisciplinario integrado por endocrinólogos, urólogos, imagenólogos, genetistas y psicólogos. En el primer caso, los pilares fundamentales del tratamiento fueron el suministro de testosterona para evitar complicaciones médicas como la osteoporosis relacionada con la deficiencia de esta hormona y el acompañamiento psicológico. En el segundo caso, se realizó el despistaje mediante estudios imagenológicos de derivados mullerianos internos y se posterga el suministro hormonal hasta la pubertad.

En ambos casos, la asesoría genética personal y familiar se basó en la ausencia de consanguinidad y de antecedentes familiares positivos que orientan al posible carácter esporádico de esas condiciones. Por otro lado, la imposibilidad reproductiva de ambos pacientes minimiza el riesgo de trasmisión, dado que en el caso 1 , la etiología de la enfermedad es una posible translocación del gen SRY hacia un cromosoma $\mathrm{X}$ o cromosoma autosómico y en el caso 2 una posible mutación génica de-novo implicada en los DSD.

En conclusión, los casos expuestos ilustran la dificultad de un reconocimiento precoz de los DSD debido a que son eventos relativamente raros. Desde el punto de vista diagnóstico, el criterio clínico debe apoyarse en técnicas citogenéticas, moleculares, bioquímicas e imagenológicas, que permitan 


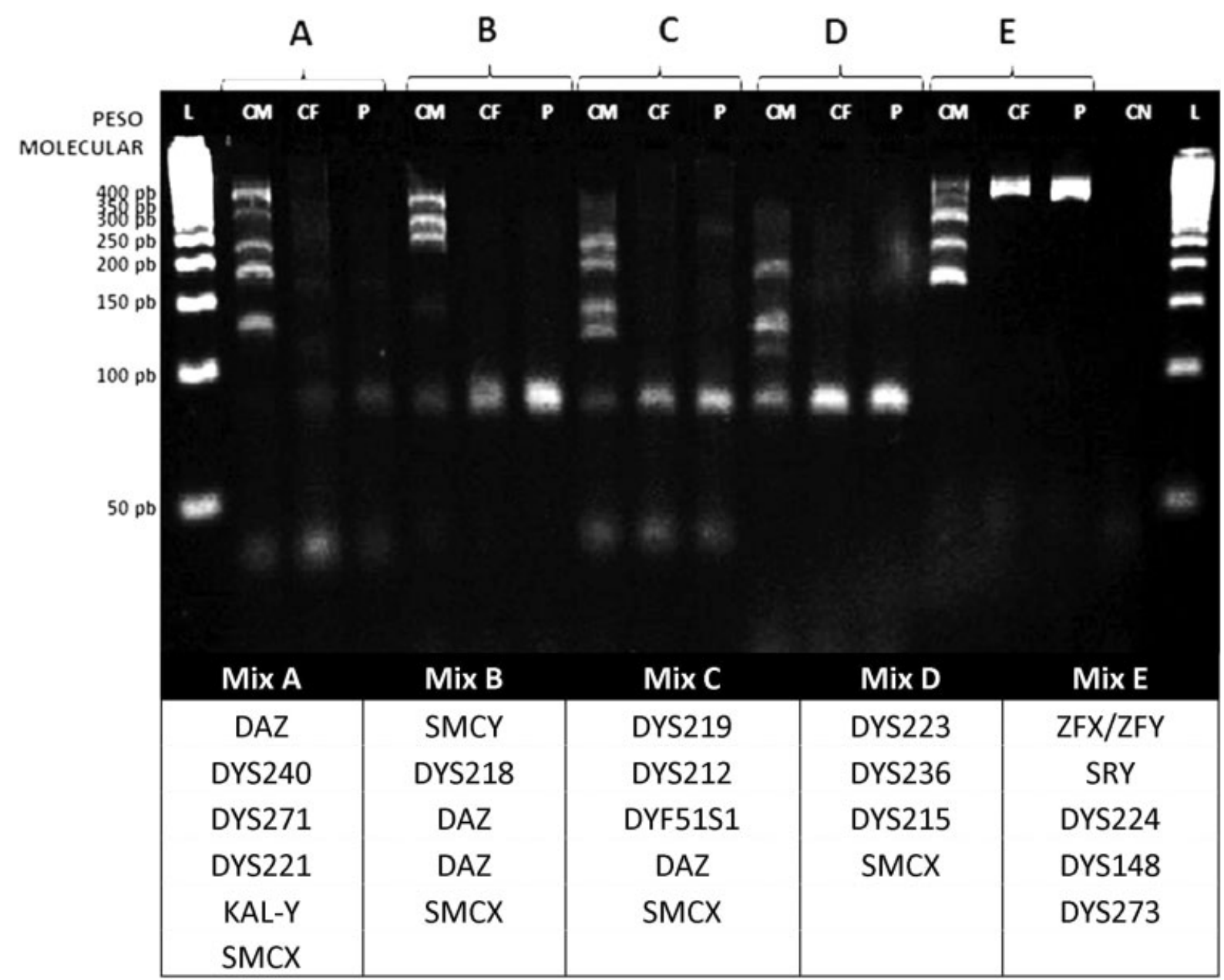

Fig. 4 Gel de agarosa grado analítico 4\% (p/v). Abreviaciones: CF, control femenino; CM, control masculino; CN: control negativo; L, marcador de peso molecular de $50 \mathrm{bp}$; $\mathrm{P}$, paciente caso 2 .

identificar los mecanismos causales de ese grupo heterogéneo de condiciones clínicas. Su manejo adecuado se basa en un enfoque multidisciplinario ya que constituyen un grupo complejo de condiciones, con implicaciones no solo clínicas sino psicológicas y sociales, por lo que siguen siendo un reto para el médico contemporáneo.

Nombre de la Institución Donde se Llevó a Cabo la Investigación

Hospital de Especialidades FFAA No.1.

Responsabilidades Éticas

Protección de personas y animales. Los autores declaran que para esta investigación no se han realizado experimentos en seres humanos ni en animales.

Confidencialidad de datos. Los autores declaran que han seguido los protocolos de su centro de trabajo sobre la publicación de datos de pacientes.

Derecho de la privacidad y consentimiento informado. Los autores declaran que en este artículo no aparecen datos de pacientes.

Conflicto de Intereses

Los autores declaran no tener ningún conflicto de intereses.
Financiación

Los estudios genéticos realizados fueron financiados por el Hospital de Especialidades Fuerzas Armadas No.1, Quito, Ecuador.

Agradecimientos

Agradecemos a los Servicios de Endocrinología del Hospital de Especialidades Eugenio Espejo y del Hospital Pediátrico Baca Ortiz por su ayuda y colaboración en la resolución de los casos reportados.

\section{Bibliografía}

1 Delachapelle A, Hortling H, Niemi M, Wennstroem J. XX Sex Chromosomes in a Human Male. Acta Med Scand 1964; $175: 412,25-28$

2 de la Chapelle A. The etiology of maleness in XX men. Hum Genet 1981;58(01):105-116

3 Jäger RJ, Anvret M, Hall K, Scherer G. A human XY female with a frame shift mutation in the candidate testis-determining gene SRY. Nature 1990;348(6300):452-454

4 Koopman P, Gubbay J, Vivian N, Goodfellow P, Lovell-Badge R. Male development of chromosomally female mice transgenic for Sry. Nature 1991;351(6322):117-121

5 Sinclair AH, Berta P, Palmer MS, et al. A gene from the human sex-determining region encodes a protein with homology 
to a conserved DNA-binding motif. Nature 1990;346 (6281):240-244

6 Ergun-Longmire B, Vinci G, Alonso L, et al. Clinical, hormonal and cytogenetic evaluation of $46, \mathrm{XX}$ males and review of the literature. J Pediatr Endocrinol Metab 2005;18(08):739-748

7 Jain M, v V, Chaudhary I, Halder A. The Sertoli Cell Only Syndrome and Glaucoma in a Sex - Determining Region Y (SRY) Positive XX Infertile Male. J Clin Diagn Res 2013;7(07):1457-1459

8 Anık A, Çatlı G, Abacı A, Böber E. 46,XX male disorder of sexual development:a case report. J Clin Res Pediatr Endocrinol 2013;5 (04):258-260

9 Kirsch S, Weiss B, Schön K, Rappold GA. The definition of the Y chromosome growth-control gene (GCY) critical region: relevance of terminal and interstitial deletions. J Pediatr Endocrinol Metab 2002;15(Suppl 5):1295-1300

10 Vorona E, Zitzmann M, Gromoll J, Schüring AN, Nieschlag E. Clinical, endocrinological, and epigenetic features of the 46,XX male syndrome, compared with 47,XXY Klinefelter patients. J Clin Endocrinol Metab 2007;92(09):3458-3465
11 Majzoub A, Arafa M, Starks C, Elbardisi H, Al Said S, Sabanegh E. $46 \mathrm{XX}$ karyotype during male fertility evaluation; case series and literature review. Asian J Androl 2017;19(02): 168-172

12 Valetto A, Bertini V, Rapalini E, Simi P. A 46,XX SRY-negative man with complete virilization and infertility as the main anomaly. Fertil Steril 2005;83(01):216-219

13 Wang T, Liu JH, Yang J, Chen J, Ye ZQ. 46, XX male sex reversal syndrome: a case report and review of the genetic basis. Andrologia 2009;41(01):59-62

14 Akinsal EC, Baydilli N, Demirtas A, Saatci C, Ekmekcioglu O. Ten cases with 46,XX testicular disorder of sex development: single center experience. Int Braz J Urol 2017;43(04):770-775

15 Zenteno-Ruiz JC, Kofman-Alfaro S, Méndez JP. 46,XX sex reversal. Arch Med Res 2001;32(06):559-566

16 Kojima Y, Hayashi Y, Mizuno K, et al. Up-regulation of SOX9 in human sex-determining region on the $Y$ chromosome (SRY)negative XX males. Clin Endocrinol (Oxf) 2008;68(05): 791-799 